\title{
Prevention of post harvest loss of tomato by Badi preparation
}

\author{
P.L. ShrivastaVA
}

Krishi Vigyan Kendra (N.D.U.A\&T), Sohaon, BALLIA(U.P.) INDIA

Email : dr.premlata99@gmail.com

SUMMARY :

A survey based study was carried out from the year 2009 to 2014 in the rural Ballia of Uttar Pradesh to know the vegetable having maximum post harvest loss, method of prevention used in rural areas to stop the spoilage, and acceptance of tomato bari as a means to prevent post harvest loss of tomato. A personal interview schedule developed was used. Fifty Female respondent were interviewed. Maximum spoilage was observed in case of tomato and no any method to prevent the spoilage. KVK analyzed the problem critically and found the solution in the form of preservation, value addition and other transformation by way of training and demonstration. Looking production, low consumption during peak period and post harvest loss of tomato KVK formulated preparation of tomato bari. Acceptability of bari as a vegetable was tested by women. Hundred per cent showed their fully acceptance. Women education, technical training and adequate extension facilities can create a positive impact leading to a better tomorrow.

KEY WORDS : Women, Education, Technical training, Adequate extension facilities, Tomato bari

How to cite this paper: Shrivastava, P.L. (2016). Prevention of post harvest loss of tomato by Badi preparation. Internat. J. Proc. \& Post Harvest Technol., 7 (1) : 162-164. DOI: 10.15740/HAS/IJPPHT/7.1/162-164 